\title{
Teacher Preparation, Professional Development, and Long-Term English Learners
}

\author{
Daniel Diego ${ }^{1, *}$ \\ ${ }^{1}$ Benerd School of Education: University of the Pacific, 3601 Pacific Ave, Stockton, \\ California, 95211, United States \\ *Correspondence: Tel: 1-916-532-4930Ｅ-mail: d_diego@u.pacific.edu
}

Received: August 17, 2013 Accepted: September 30, 2013 Published: October 13, 2013

doi:10.5296/ije.v5i4.4140ＵRL: http://dx.doi.org/10.5296/ije.v5i4.4140

\begin{abstract}
This article presents a synthesis of research linking Long-Term English Learners (LTELs) and the underprepared schools and teachers they have encountered. The purpose of this article, though small in scope, is to explore the policies, practices, and conditions surrounding teacher preparation and professional development in relation to the growing number of LTELs. While the standards designed to guide curriculum have paid little attention to second-language development and differ only slightly from those designed for native English speakers, the number of LTELs in the United States has continued to rise therefore causing the factors which impact the failure of English Learners (ELs) to achieve reclassification as English Proficient students to become an issue of focus in education. Multi-cultural theorists have argued that diversity issues are central to the rest of the curriculum and must be infused throughout courses, field experience requirements, and professional development in order to strengthen preservice and inservice teachers' multi-cultural relational capacity and knowledge of instructional strategies for ELs and LTELs. While other nations have taken the initiative to produce highly effective, experienced, and dedicated teachers there remains a desperate need for a general consensus to build a policy infrastructure that supports reform with the intention of preventing future harm to the diverse student population in the U.S.
\end{abstract}

Keywords: Long-Term English Learners; English Learners; field experiences; professional development; multi-cultural; policy 


\section{Introduction}

One of the greatest challenges currently facing education in the U.S. is providing educators and preservice teachers with the knowledge, skills, support, and experiences necessary to meet the demands of educating the burgeoning population of English Learners (ELs) (Valentine, 2006; Vogt, 2009). According to national data by NCES (2003), the percentage of all public school students from ethnic minority groups has increased drastically, from $22 \%$ in 1972 to 39\% in 2000, and remains on the rise (Durgunoglu \& Hughes, 2010). Despite the fact that schools in the U.S. are steadily becoming more ethnically diverse, many educators, preservice teachers, and educational institutions remain underprepared to provide high-quality multi-cultural instruction to their ELs and Long-Term English Learners (LTELs) (Coady, de Jong, \& Harper, 2011; Nieto, 2005). According to the AERA Panel on Research and Teacher Education (Cochran-Smith \& Zeichner 2005), teacher preparation must be improved, although vast differences in opinions about how, why, and for what purposes persist. While many preservice teachers have been introduced and exposed to EL instructional strategies, along with the theories and research to support them in their university coursework, lack of academic achievement among our ELs and LTELs is a strong indicator that it is time to re-assess and rethink educational policies of the past (Menken, Kleyn, \& Chae, 2009).

Currently, an issue that has gained attention in education is the growing population of LTELs (Menken et al., 2009). While a universally agreed upon definition of an LTEL has not been reached, California has taken the lead with the 2012 adoption of Assembly Bill 2193 section 313.1. The bill defines an LTEL as an English Learner who has been enrolled in the U.S. school system for more than six years without demonstrating an increase in proficiency level above far-below basic or below basic (Assembly Bill No. 2193). Although U.S. history is steeped in immigration and our schools have long housed students from varying ethnic and linguistic backgrounds, our LTELs remain a population we have ignored, harmed, and failed in the past (Olsen, 2010). Research has shown student achievement to be directly related to the type of preparation their teacher has received (Al-Bataineh, 2009; Cochran-Smith \& Zeichner, 2005), yet preservice teachers have often graduated with little or no knowledge or experiences to support ELs academics, linguistics, and cultures (Webster \& Valeo, 2011). Multi-cultural theorists have argued that diversity issues are central to the rest of the curriculum and must be infused throughout courses and field experience requirements rather than contained in one or two optional multi-cultural courses (Cochran-Smith, 2008; Nieto, 2000; Villegas \& Lucas, 2002). Due to our diverse society, it seems reasonable to suggest that all preservice and inservice teachers' multi-cultural relational capacity and knowledge of instructional strategies for ELs and LTELs would be greatly strengthened with the addition of related field experience requirements and up-to-date professional development opportunities. The purpose of this article, though small in scope, is to explore factors in teacher preparation and education that have contributed to the growing LTEL population. 


\section{Critical Analysis}

As the number of ELs in the U.S. continues to rise, substantial numbers of mainstream classroom teachers are being held accountable for the responsibility and education of their ELs (Durgunoglu \& Hughes, 2010; Vogt, 2009). Despite research that has suggested teacher preparation accounts for a significant percentage of variance in student achievement (Beare, Marshal, Torgerson, Tracz, \& Chiero, 2012; Darling-Hammond, 2011), many teachers remain under-prepared to provide higher-caliber instruction to ELs and LTELs (Coady et al., 2011). A number of teacher education reformers have also critiqued the lack of connection between teacher preparation programs and their immediate communities (Cochran-Smith \& Lytle, 2009). In accordance, Valentine (2006) has demonstrated, many preservice teachers hold underdeveloped personal understandings of the academic and multi-cultural needs of ELs and LTELs, due to inadequacies of certain preparation programs. Indeed, while many preservice teacher preparation programs have attempted to develop appropriate academic and multi-cultural knowledge and attitudes (Darling-Hammond, 2008), research has suggested the need for teachers prepared to teach differently and to participate in major efforts to change certain traditional ways of thinking about teaching, education, and social change (Cochran-Smith, 2001). In order to provide high quality instruction to all students, Webster and Valeo (2011) argue that preservice teachers must exit their preparation programs with unbiased, up-to-date understandings of the social, cultural, and academic needs of EL and LTEL populations as well as the knowledge and know-how to reflect, assess, and differentiate practice as needed.

Aside from inadequate teacher preparation programs, ELs and LTELs in the U.S. have also been dealt a disservice by insufficient resources and ill-equipped schools (Calderon, 2008; Calderon, Slavin, \& Sanchez, 2011; Menken \& Kleyn, 2009). For example, the average English as a Second Language (ESL) or bilingual program at the secondary level has not been designed to explicitly teach LTELs the literacy skills they need across all content areas, as they were designed to meet the needs of ELs who have entered high school with adequate prior education and native language literacy skills (Menken \& Kleyn, 2009). Although school districts have been required to provide accommodating services to ELs, the U.S. Department of Education has not offered States any policy suggestions in instructing, assessing, identifying or placing LTELs (Calderon et al., 2011). Furthermore, State standards that guide curriculum for ELs, and in effect LTELs, have paid little attention to second-language development and differ little from the standards designed for native English speakers (Calderon et al., 2011). In order to prevent continued harm to our ELs and LTELs, Calderon et al. (2011) have demonstrated that, aside from developing a nation-wide universal definition of LTELs and appropriate standards, field experiences, professional development opportunities, school reform, and academic and multi-cultural instructional strategies for ELs must be examined with the intention of reform and implementation at all levels. 


\section{Inquiry Questions}

1. How are teacher preparation programs preparing teacher candidates to educate English Learners (ELs) and Long-Term English Learners (LTELs)?

2. What are the challenges associated with preparing educators, schools, and districts for educating Long-Term English Learners (LTELs)?

3. In what ways does participation in field experience requirements influence teacher candidates' preparation to teach ELs and LTELs?

\section{Set of Findings from Literature}

Despite the fact that most preservice teacher preparation programs have reportedly incorporated diversity and multi-cultural content and instructional strategies into the curriculum, external examinations have often proven otherwise (Cochran-Smith, 2003). Although insufficient, national data and research on LTELs has suggested that significant numbers of these students have experienced high rates of disparity and gone un-noticed or perceived as failures in many schools across the U.S. (Menken et al., 2009). With the existence of such disparity between the success of ELs and that of native English speaking students, many researchers have suggested that schools, districts, and preparation programs deconstruct prior ways of thinking about academic and multi-cultural instructional strategies for ELs and LTELs (Calderon, 2008; Calderon et al., 2011). On a deeper level, multi-cultural theorists and practitioners have argued the need for teachers to understand the meaning of culture as an impact on learning and education; the nature of ethnic, racial, and urban cultures; and the role of culture in socialization, interaction, and communication (Cochran-Smith, 2003; Gay \& Howard, 2000; Villegas \& Lucas, 2002). Furthermore, multi-cultural theories have also suggested the need for preservice teachers to develop critical cultural or socio-cultural consciousness and competence to work effectively and draw on community, family, and cultural resources to learn about the cultures of their students (Cochran-Smith, 2003; Gay, 1993; Villegas \& Lucas, 2002). The following literature has highlighted three areas in the U.S. educational system in need of reform and further investigation for the sake of EL and LTEL populations: public school reform, preservice teacher preparation programs, and inservice teacher professional development.

\subsection{Why LTELs?}

As the percentage of ELs making their way into ill-equipped mainstream classrooms has increased over the last decade (Olsen, 2010), researchers have uncovered multiple factors and characteristics related to LTELs. In doing so, Calderon et al. (2011) have identified two main types of LTELs: (a) ELs who have experienced extended periods of time in which they received inconsistent schooling, frequent movement in and out of and between bilingual education, ESL, and the mainstream classrooms in the U.S. (Menken \& Kleyn 2009; Olsen, 2010); and (b) transnational ELs who have moved back and forth between the U.S. and their family's native country, while attending schools in both countries (Menken \& Kleyn, 2009). 
Regardless of the type of LTEL, current research has shed light on several other common characteristics: LTELs are typically found in grades 6-12 and are often orally bilingual but demonstrate limited literacy skills in their native language. Furthermore, LTELs often perform below grade level in school, especially in reading and writing, as their academic English literacy skills have remained under-developed.

When compared to their native English speaking counterparts, ELs and other minority populations have often experienced a disproportionate amount of underprepared teachers due to a lack of data and familiarity (Menken \& Kleyn, 2009; Nieto, 2005). This is exemplified by the fact that approximately one in three school districts in the U.S. have developed a formal process for identifying and monitoring ELs and LTELs (Olsen, 2010). According to Olsen (2010), there has been an increasingly strong body of research to describe the important role language support and instruction has played in developing English literacy, yet the number of ELs receiving primary language support and instruction has dwindled to approximately $5 \%$, missing the opportunity to hone native language skills.

\subsubsection{Elementary/primary school reform}

With dozens of languages spoken in our schools, and as many cultures being represented, LTELs are currently among the fastest growing student populations in the U.S., with the majority speaking Spanish (Menken et al., 2012). Having recognized the need to accommodate these types of students, Calderon et al. (2011) have asserted that the quality and type of instruction is what matters most in educating and preventing future LTELs. In their assertion, Calderon et al. (2011) have emphasized the deconstruction and examination of school structures, leadership, language and literacy instruction, language integration, and content instruction in secondary schools. Their research has exposed a need for schools and districts to promote balanced bilingualism and biliteracy development by restructuring secondary ESL classes to teach LTELs separately from ELs new to the U.S., while emphasizing literacy development across all content areas (Krashen, 2005; Menken \& Kleyn, 2009). Furthermore, Calderon et al. (2011) have suggested that on-going cooperative learning and professional development, parent and family support teams, tutoring, and close monitoring of implementation and outcomes are necessary components for reform of this nature. While it has often been difficult for schools and teachers to include less prevalent languages, the aid of volunteers or bilingual professionals, after school enrichment programs, native language text translations when possible, and multi-cultural professional development has shown promise for stronger refinement of native language literacy skills (Menken \& Kleyn, 2009).

On a wider scale, research has shed light on the need for schools in the U.S. to develop more coherent language policies and further reduce the movement in and out of bilingual education, ESL classes, and mainstream programs. In addition, researchers have expressed the need for schools to constantly accumulate, maintain, and utilize a collection of on-going formative data on learning, teaching, attendance, behavior, and other important intermediate outcomes of their ELs and LTELs (Calderon et al., 2011; Krashen, 2005; Menken \& Kleyn, 2009). To ensure transparency of issues surrounding EL and LTEL success and failure, Calderon et al. 
(2011) have suggested schools share information about their ELs and LTELs, widely monitor learning, and include strong, on-going professional development for all staff. Furthermore, schools and educators require more accurate data regarding academic and multi-cultural instructional strategies for LTELs, the individuals themselves, and the consistency of their education (Menken \& Kleyn, 2009).

\subsubsection{Preservice preparation program reform}

According to Nieto (2005), a widely cited study from the National Commission on Teaching and America's Future (1996) found significantly higher gains in achievement by students who were assigned to several highly performing teachers in a row, as opposed to those assigned to less prepared teachers. This study further demonstrated that teacher's influence had effects that carried over into later years. While there has been a general agreement regarding the need for high quality teachers and instruction, institutional and government policies that have supposedly committed to the goals of providing all children equal access to highly qualified teachers often turn out to be strikingly different from, and sometimes diametrically opposed to, one another in implementation and ramifications (Cochran-Smith, 2003). According to Cochran-Smith (2003), these differences have accounted for dramatically different takes on teacher preparation for diversity, multicultural teacher education, and what it means to be highly qualified. Given this reality, research and discussions must be conducted with regards to what it means to recruit, prepare, and retain teachers to work with diverse students who are often vastly different from their teacher in background and experience (Nieto, 2005). Although there has been a growing number of preservice preparation programs in the U.S. redesigning their frameworks and structures to better suit diverse populations, many universities and preparation programs remain in need of reform on some level for the sake of ELs and LTELs (Darling-Hammond \& McLaughlin, 2011).

In accordance, certain states have taken steps to ensure teachers are capable of teaching learners from different backgrounds (Jaquith, Mindich, Wei, \& Darling-Hammond, 2011). Teacher preparation programs, such as the University of Wisconsin's Teach for Diversity Program and those at Emory University, have been restructured to explicitly prepare teachers to construct culturally responsive curriculum and pedagogy (Cochran-Smith, 2003; Irvine \& Armento, 2001). Other states, including Colorado, Connecticut, Massachusetts, Missouri, Vermont, and New York, have added one or two-year graduate programs, while some have even included five year programs that begin during the undergraduate years and continue through the graduate level, allowing students to focus exclusively on the task of preparing to teach (Scherer, 2012). Several of these States have also implemented fully funded mentoring programs in which time is allocated for expert teachers to coach preservice teachers on a regular basis in lesson planning, problem solving, and reflecting on instructional skills (Scherer, 2012). In these programs, emphasis has been placed on teaching specific practices applicable to the diversity found in classrooms, implementing those practices, problem solving, and then reflecting on the experience and reapplying it back to the classroom (Scherer, 2012). Teacher preparation courses and student teaching in such programs are 
woven around each other and often enroll students in student teaching from the time they enter through the time they complete the program (Scherer, 2012).

According to Pepper, Hartman, and Blackwell (2012), many teacher preparation programs have created stronger links between course content and practical application due to prior criticism as being too theoretical, having little connection to practice, and lacking multi-cultural community-based field experience requirements. Many of these programs have joined with school districts to create Professional Development Schools (PDSs) which have provided preservice teachers paths to teaching while allowing them to work with expert practitioners, mentors, university adjuncts, and teacher leaders (Darling-Hammond \& McLaughlin, 2011). The PDS concept was originally developed by the Holmes Group over 20 years ago with six general guiding principles. According to the guidelines, PDS sites must be committed to: (a) teaching for understanding rather than a factual recall, (b) organizing classrooms and schools as learning communities, (c) setting ambitious goals for all students, (d) establishing supports for continual learning among all students and staff, and (e) making reflection and inquiry the central feature of the school. However, over time, the meaning and purpose of PDSs was loosely adopted to refer to any school-university relationship that engaged in preservice teacher preparation (Pepper, Hartman, \& Blackwell, 2012). Since this idea varied greatly from the original concept, the National Association of Professional Development Schools (NAPDS) decided to redevelop a more clear set of guidelines which required PDS partnerships to: (a) craft a comprehensive mission statement; (b) commit to the preparation of future educators; (c) provide on-going professional development for all participants; (d) commit to innovative and reflective practices; (e) engage in widespread dissemination of their work and its impact on student learning; (f) articulate an agreement of roles and responsibilities; (g) sustain a forum for on-going governance, reflection, and collaboration; (h) determine formal roles across institutional settings; and (i) share resources, as well as reward and recognize participants. By enabling teachers, teacher educators, and researchers to collaboratively carry out practice-based and practice-sensitive research, PDSs have provided reliable structures and opportunities for new teachers to practice instructional decision-making and self-reflection strategies (Cochran-Smith \& Zeichner, 2005; Darling-Hammond \& McLaughlin, 2011).

According to Fitts and Gross (2012), for preservice teachers to thoroughly grasp the full extent of teachers' roles and responsibilities, as well as the process of second language acquisition and programs, such as bilingual instruction, time spent in the classroom is a major factor. Similar studies presented by Al-Bataineh (2009), Darling-Hammond (2011), Morrell (2010), and Pepper et al. (2012) have demonstrated that significant problems with preservice preparation have been directly linked to the lack of time preservice teachers spend in the classroom. Furthermore, the center for the Study of Teaching Policy (2001), the AERA Panel on Research and Teacher Education (Cochran-Smith \& Zeichner, 2005), and the National Council for Accreditation of Teacher Education (NCATE) (2010) have all strongly encouraged year-long field experience placements (Pepper et al., 2012). Likewise, according to Pepper et al. (2012), participation in a year-long internship or field experience has shown to provide optimal opportunities for preservice teachers to thoroughly conceptualize 
applications of theoretical models as well as develop a firm overview of classroom management and organization, student growth, and potential challenges associated with being a teacher.

Calderon et al. (2011) have advocated the need for preparation programs to: (a) work to build multi-cultural knowledge and skills for EL instruction and assessment, (b) provide provisions for struggling students, and (c) offer innovative approaches to curriculum through comprehensive field experience requirements and aligning coursework. Furthermore, researchers such as Darling-Hammond and Cochran-Smith have expressed the need for field experience requirements to promote an understanding of the social, cultural, and academic contexts of all students, especially our ELs and LTELs. According to AERA Panel on Research and Teacher Education (Cochran-Smith \& Zeichner, 2005), there has been almost no research conducted on this aspect of diversity, therefore research on the preparation of educators to teach underserved populations must pay close attention to the preparation of teachers to teach ELs and LTELs. Until schools and policy makers address the enormous inequalities in students' access to qualified teachers, other reforms would have little effect on student achievement (Nieto, 2005).

Although it is difficult to reach a consensus on the most effective type of field experience or teacher preparation programs, researchers such as Darling-Hammond (2011) have explained that quality teacher preparation programs are first and foremost coherent and organized around interconnected coursework, theory, and field experience requirements. Similarly, the AERA Panel on Research and Teacher Education (Cochran-Smith \& Zeichner, 2005) has emphasized teacher preparation programs across the U.S. that have included introductory in-class field observations, method courses that include field experience alliance, and community-based field experience requirements and student teaching with diverse populations. The length of the field experience requirements in these programs have ranged from a few hours a week for several weeks to daily, full-time work across two semesters. These requirements have sought to provide preservice teachers with ample opportunities to work with and learn from expert and master teachers, while gaining a deeper understanding of how students learn, how to assess learning, and how to implement effective strategies for working with diverse populations (Calderon et al., 2011; Darling-Hammond, 2011). In order to move in the right direction, however, consensus must be reached regarding investment in sustained infrastructure reform and the development of institutional and environmental supports to promote the spread of ideas and shared learning (Darling-Hammond \& McLaughlin, 2011).

Research has demonstrated that EL success in school, on top of being influenced by the academic knowledge and skills their teachers hold, is also influenced by the biases, misconceptions, and experiences of their teachers concerning areas such as language, ethnicity, gender, and socio-economic status (Burbank, Ramirez, \& Banks, 2012; Crawford, 2005; Cummins, 2005). According to Burbank, Ramirez, \& Banks (2012), some teacher preparation programs have also failed to teach preservice teachers to develop reflection and problem solving skills to assess issues and challenges from multiple perspectives, and deconstruct misconceptions, routines, practices, and other procedures that have been taken for 
granted. As a consequence, preservice teachers often end their preparation with unexamined or unquestioned beliefs toward diverse populations such as ELs (Burbank et al., 2012). Further research by Cochran-Smith (2001) has described quality multi-cultural teaching as: (a) actively working against assumptions and arrangements of education and society that reinforce inequities, disrespect and oppression; (b) actively working for the effective use of marginalized groups' knowledge, traditions, and ways of thinking in classrooms and schools; and (c) recognizing, respecting, and reflecting on all social, racial, and cultural groups. Teaching reflectively, through inquiry and understanding, is profoundly practical yet deeply intellectual in dealing with classroom decisions, choices of materials and texts, interactions with students and families, the uses of formal and informal assessments, and continuously constructing understandings, interpretations, and questions (Cochran-Smith, 2001). This also includes the ability to analyze messages about race, class, culture, and language background (Cochran-Smith, 2008). According to Fitts and Gross (2012), research in the past that has explored preservice and new teacher beliefs towards bilingual students and ELs have often revealed negative, simplistic, and erroneous views. In an attempt to counter these potentially negative outcomes, certain teacher preparation programs have sought reform as a means to provide preservice teachers with strong knowledge and first-hand experiences related to effective primary and secondary language support and understanding (Burbank et al., 2012; Menken \& Kleyn, 2009; Nieto, 1994; Olsen, 2010).

According to Fitts and Gross (2012), developing positive attitudes towards linguistic diversity is fundamental for developing effective and appropriate EL and LTEL academic and multi-cultural instructional strategies. Furthermore, Webster and Valeo (2011) have argued that simply providing opportunities for preservice teachers to work in classrooms is not enough; preservice teachers require opportunities to work with ELs and LTELs under the guidance of expert teachers while practicing strategies learned in well-developed coursework. Research has demonstrated that teachers who have developed positive attitudes about linguistic diversity expressed higher levels of competency and held higher standards for ELs (Fitts \& Gross, 2012). Studies have also shown, that field experience requirements equipped with appropriate scaffolding and mentoring from university faculty and expert teachers, has assisted preservice teachers in developing intercultural sensitivity, empathy, and insight towards culturally appropriate teaching (Fitts \& Gross, 2012). Based on their analysis of demographic trends, Villegas and Lucas (2004) have concluded that increased diversity in the teaching force will provide needed role models for all students, while infusing essential cultural knowledge into the classrooms. Furthermore, other research has demonstrated higher likelihood of linguistic and academic development among ELs directly linked to the experiences and background of minority and non-traditional preservice teachers (Clewell \& Villegas, 2001; Cochran-Smith, 2008). Lack of deeper multi-cultural understanding, Fitts and Gross predict, will lead to misconceptions, biases, and negative attitudes towards ELs as well as the misuse of accommodations and modifications (Fitts \& Gross, 2012). Quality field experiences, according to Webster and Valeo (2011), must provide preservice teachers with constructive feedback, opportunities to observe the implementation of successful and effective strategies, and time to experiment with their own tactics. Furthermore, Cochran-Smith (2008) has described the importance of preservice teacher preparation 
programs that have encouraged and taught students to challenge, when need be, classroom and societal practices, policies, labels, and assumptions that reinforce inequities. Likewise, others have advocated calling attention to what is left out, implied, or veiled in the curriculum (Cochran-Smith, 2008) as well as questioning norms or preconceived notions about pedagogy, growth, learning, experience, expectations, or family (Cochran-Smith, 2008).

In recent years, Finland, Singapore, and South Korea have moved to the top of international rankings in student achievement and attainment with other nations, such as Australia, Canada, New Zealand, and parts of China, following suit with development of strong educational systems (Darling-Hammond, 2005). Finland, Singapore, and South Korea have created progressive systems by investing in ambitious educational programs that allow for wider access (Darling-Hammond, 2005; 2010). Unlike the U.S., these nations have taken steps to adequately fund schools and include incentives ranging from more benefits for educators teaching in rural, urban, or disadvantaged school populations to smaller class sizes, less in-class teaching time, and additional stipends and pay salaries competitive with other careers (Darling-Hammond, 2010). As a result, these nations have produced highly effective, experienced, and dedicated teachers in schools, ensuring a foundation and future for strong learning (Darling-Hammond, 2010).

When it comes to preservice teacher preparation, these nations have also invested in strong teacher education programs that work to recruit top students while completely subsidizing extensive training programs and providing financial support for preservice teachers as they learn to teach (Scherer, 2012). These nations and others alike, have redesigned teacher preparation programs to increase teachers' pedagogical knowledge, skills, and mastery of certain content areas (Darling-Hammond, 2010). Some of these nations have even added a full year or more of field experience requirements in what they consider to be a model school, allowing preservice teachers to participate in problem-solving groups that engage in planning, action, reflection and evaluation (Darling-Hammond, 2010). Overall, the consensus in these nations has grown very supportive of substantial participation and collaboration in regards to decision making about curriculum, instruction, assessment, and professional development. Strong support and funding for on-going teacher professional development, collaboration, and learning in these nations has ensured quality mentoring for beginning and preservice teachers. According to Darling-Hammond (2010), these nations have also encouraged consistent, long-term reforms by setting goals for expanding, equalizing, and improving their education system. Steady implementation of these goals, along with thoughtful investments in a high-quality educator workforce, school curriculum, and teaching resources, has laid the foundation for success

\subsection{Professional Development Reform}

According to Darling-Hammond \& McLaughlin (2011), effective professional development involves educators as both learners and teachers while allowing them to struggle with the uncertainties that accompany each role. Therefore, quality professional development today must provide opportunities for teachers to reflect critically on their practice and fashion new knowledge and beliefs about content, pedagogy, and students. Furthermore, 
Darling-Hammond (2011) has examined several high performing states' frameworks for supporting advanced levels of professional development in which high participation rates were found in a wide array of professional development programs, ranging from teacher induction to curriculum support and study groups focused on specific areas (Darling-Hammond, 2012). While the approaches to professional development in each state varied, the states reviewed still shared key characteristics and similar challenges. All of the high performing states have designed and implemented professional development standards and mentoring programs for beginning teachers (Scherer, 2012), as well as an organization or professional board to oversee teacher licensing, professional teaching standards, and professional development (Darling-Hammond, 2005). Most of these programs have also required professional development plans for teachers and minimum levels of professional development for license renewal (Darling-Hammond, 2005; Scherer, 2012). Although designing, measuring, and providing effective professional development is a complex undertaking for schools and districts, studies have indicated professional development to be most helpful for teachers of ELs when it provided opportunities for hands-on practice with teaching techniques applicable to their classrooms, in-class demonstrations with their own or a colleague's students, and personalized coaching (Calderon et al., 2011).

Additional studies have been conducted regarding teacher professional development in nations outside the U.S. According to Darling-Hammond (2005), in the last 20 years, many countries have added in-depth pedagogical study and practicum to a base of strong undergraduate preparation in the disciplines. In these countries, teachers have typically spent 15-20 hours per week in their classrooms, with the remaining time spent developing and refining their practice collaboratively with colleagues (Darling-Hammond, 2010). In Japan and China, for example, Darling-Hammond (2005) found that teachers routinely worked with their colleagues on designing curriculum, polishing lessons, observing one another's teaching, participating in study groups, and conducting research on teaching. Furthermore, Japanese schools have allocated 20 or more hours a week for collegial work and planning, teacher observations of other classrooms and schools, and providing educators with demonstrations of teaching strategies (Darling-Hammond, 2005). In contrast, Darling-Hammond has explained that what little opportunities, if any, U.S. teachers have been provided for professional learning or collegial work has commonly taken place in workshops or courses held after school, on weekends, or during a small number of professional development days.

Based on the literature and research, professional development that has focused on deepening teachers' understandings of the processes of teaching and learning, and of the students they teach, has proven most influential (Darling-Hammond \& McLaughlin, 2011). Furthermore, certain teacher professional development structures for individual and organizational learning have added to the effectiveness by including opportunities for teachers to share what they know and what they want to learn while linking their learning to the contexts of their practice (Darling-Hammond \& McLaughlin, 2011). These professional development programs have been grounded in inquiry, reflection, and experimentation with on-going and intensive support provided by modeling, coaching, and collective reflection (Darling-Hammond, 2005; Darling-Hammond \& McLaughlin, 2011). Central to this type of growth, however, are 
structures that have broken down isolation and empowered teachers with professional tasks arenas for reflecting on the standards (Darling-Hammond \& McLaughlin, 2011).

Based on literature and research, there has been a desperate need for a general consensus in the U.S. to build a policy infrastructure that supports reform on a wide scale with goals of preventing future harm to our students, especially our diverse ELs and LTELs (Menken \& Kleyn, 2009; Olsen, 2010; Scherer, 2012). Currently, however, a policy problem exists that has extended beyond mere support for teachers' acquisition of new skills or knowledge (Cochran-Smith, 2001; Darling-Hammond \& McLaughlin, 2011). This policy problem has been rooted in the fact that there is no consensus in the U.S. about how and where teachers should be educated, what they should or shouldn't learn, and what theories of teaching and learning should guide their preparation (Cochran-Smith, 2001; Cochran-Smith \& Zeichner, 2005). Many of the most contentious debates about outcomes in teacher education have stemmed from two fundamentally different approaches to teacher education reform representing two fundamentally different views of the purposes of schooling. According to Cochran-Smith (2001), advocates of the first approach, reform through professionalization, have argued that public education is vital to a democratic society and all students deserve fully-licensed, well qualified teachers. On the other hand, the deregulation approach has fed off the decline of public confidence in education, arguing a market approach to the problem of teacher shortages, so that larger numbers of college graduates can enter the profession without any teacher preparation (Cochran-Smith, 2001). With other nations having taken the lead in reform and higher allocation of educational resources and time for collaboration, certain states, such as Colorado, Massachusetts, and Vermont, have attempted to follow suit. Education reform in the U.S. is a huge endeavor to undertake; although states such as these have begun to develop high quality learning opportunities, the work of high performing nations and states must be closely examined, more research must be conducted, and a policy consensus must be reached if the U.S. is to develop an education infrastructure that will support reform on a wide spread scale (Scherer, 2012). According to Darling-Hammond (2005), approximately 52\% of U.S. educational dollars make it to the classroom, while other industrialized nations have ensured roughly three-fourths of their education resources are spent directly on instruction. Classroom teachers in the U.S. make up about $43 \%$ of education staff, yet in other high-performing nations classroom teachers have accounted for $60-80 \%$ of all staff (Darling-Hammond, 2005). The work of Darling-Hammond (2011) has shown that when states and schools in the U.S. have re-allocated staff and educational resources more directly to the classroom, student achievement among ELs has grown along with teacher quality, commitment, and self-efficacy. Although research has shown that some resources are available in the U.S. school systems, policy makers must agree upon the appropriate distribution of funds, support, and resources in order to improve the quality of teaching. 


\section{Recommendation for Future Inquiry}

Although many researchers have examined teacher education in the U.S. and provided valuable information about the ways in which teacher preparation programs influence teacher quality and preparedness, according to the AERA Panel on Research and Teacher Education (Cochran-Smith \& Zeichner, 2005), few definitive statements can be made about the effects of specific models for preservice education. According to the AERA Panel on Research and Teacher Education, researchers that have reviewed and studied preparation programs have produced inconsistent and contradictory results across various studies, thus limiting their usefulness. Based on prior literature and research, in order to come closer to reaching a consensus, future research and study must include deeper discussion and descriptions of the following: (a) teacher preparation and professional development programs, (b) the state policy contexts in which programs are embedded, (c) the school and community context in which program graduates teach, (d) teacher evaluation, and (e) the failure to distinguish effects of programs from the influence of the characteristics that preservice teachers bring to the programs (Cochran-Smith \& Zeichner, 2005).

Given the growing diversity of the student population, the continuing predominance of non-minority teachers, and the general belief in the desirability of a diverse teaching force, future demographic and multi-cultural research is needed which focuses on the following: (a) the race and ethnicity of preservice and inservice teachers; (b) development of comprehensive and up to date demographic profiles about preservice and inservice teachers to better understand the effects or influence of teacher preparation and professional development geared for EL and LTEL instruction: (c) investigation of demographic variables related to how teachers are prepared and where they teach; (d) baseline comparisons with other professions to better understand the lack of diversity among teachers and indicate different policy implications, particularly if the problem is unique to teaching; (e) whether and how the non-representative profile and distribution of teachers influence student achievement and outcomes (Calderon, 2008; Calderon et al., 2011; Cochran-Smith \& Zeichner, 2005; Menken \& Kleyn, 2009). While educators, researchers, and policy makers hold different beliefs as to the most appropriate means for educating LTELs, in order to pinpoint the exact results of a particular program or approach, more research is needed examining specific field experience requirements and locations, who is supervising the preservice teachers engaged in the field experience, and what is being taught (Cochran-Smith \& Zeichner, 2005).

\section{Conclusion}

In elementary schools across the U.S., ELs have commonly received thirty minutes or less of English as a Second Language (ESL) instruction while attending general education classes for the rest of the day, usually with teachers who are underprepared to educate them (Calderon et al., 2011). Though ELs have strikingly diverse levels of skills, they are typically lumped together, especially at the secondary level, with one teacher or program to address their widely different needs. Certain in-school factors, coupled with outdated teacher preparation and professional development programs, have perpetuated the achievement 
disparities of our ELs and LTELs (Calderon et al., 2011). In order to counter these achievement disparities, closing similar gaps in teacher preparation programs and on-going professional development is vital (Calderon, 2008; Calderon et al., 2011). Unfortunately, while many top researchers have offered characteristics of quality preparation, there has been no definitive consensus as to the effectiveness of one type of preparation program over the other. Since many of today's ELs and LTELs spend much of their time in regular classrooms with teachers who feel that they are underprepared to meet their needs (Calderon et al., 2011), ensuring that all preparation programs include thorough and adequate multi-cultural field experience requirements is vital to our future.

Although there are many issues associated with LTELs, two of the most agreed upon areas in need of deconstruction and reform have been language support and teacher preparedness (Calderon, 2008; Calderon et al., 2011; Menken et al., 2009). Based on prior research, there is and has long been the need for: (a) the constant collection and use of on-going formative data on LTEL learning, teaching, attendance, behavior, and other important intermediate outcomes; (b) a strong focus on intensive and on-going academic and multi-cultural professional development for all educators and administrators with opportunities for peer and expert coaching; (c) a system of organization that shares information about LTELs widely while monitoring the quality of teaching and learning carefully; and (d) two-fold bilingual programs based on the needs of the school's ELs which teaches reading in the native language while transitioning students to English instruction (Calderon et al., 2011). The lack of appropriate reforms, implementation, and policy consensus, combined with underprepared preservice teachers and preparation programs, has impeded our teachers' and schools' abilities to address the social and academic needs of LTELs at the classroom level (Menken \& Kleyn, 2009).

Considering the lack of effective language support and teacher preparedness for LTELs, educators, administrators, policy makers, and researchers must have more open discussions about reform and dig deeper into the policies, practices, conditions, and teacher preparation and professional development programs related to ELs and LTELs. It is time to recognize that weak and outdated programs have inflicted harm upon ELs in the U.S. and caused them to fall behind. Although the idea of reform for equitable education is not a new one, U.S. schools cannot fulfill this ambitious and noble undertaking until society as a whole is ready to commit to sustaining education as a public trust and a promise to future generations (Nieto, 2005). Therefore, once deeper and more descriptive research regarding LTELs and teacher preparation and professional development is conducted, and an overall policy consensus is reached, schools and districts can begin to provide their diverse student populations with the just education they deserve, in attempt to foster long-term success for all. 


\section{References}

Al-Bataineh, A. (2009). An examination of preservice teacher preparedness: A cooperating teacher perspective. The International Journal of Learning, 16(5), 231-249.

Assembly Bill No. 2193 section 313.3, an act to amend Section 52059 of, and to add sections 313.1, 313.2, and 313.3 to, the Education Code, relating to English learners, (2012).

Beare, P., Marshall, J., Torgerson, C., Tracz, S., \& Chiero, R. (2012). Toward a culture of evidence: Factors affecting survey assessment of teacher preparation. Teacher Education Quarterly, 39(1), 159-173.

Beers, B. (2006). Learning driven schools. Association for Supervision and Curriculum Development. Alexandria, VA.

Burbank, M. Ramirez, L., \& Bates, A. (2012). Critically reflective thinking in urban teacher education: A comparative case study of two participants' experiences as content area teachers. Professional Educator, 36(2), 1-17.

Calderon, M. (2008). Expediting language, literacy, and learning for adolescent ELLs. In The STARlight - Research and Resources for English Learner Achievement, Santa Clara, CA: California STARlight Consortium, 3(1).

Calderon, M., Slavin, R., \& Sanchez, M. (2011). Effective instruction for english learners. Future of Children, 21(1), 103-127. http://dx.doi.org/10.1353/foc.2011.0007

Center for the Study of Teaching and Policy. (2001). Teacher preparation research: Current knowledge, gaps, and recommendations: A research report prepared for the U.S. Department of Education and the Office for Educational Research and Improvement. Washington, D.C.: Author. Retrieved from http://depts.washington.edu/ctpmail/publications/reports.shtml

Clewell, B.C., \& Villegas, A. M. (2001). Ahead of the class: A handbook for preparing new teachers from new sources. Washington, DC: Urban Institute.

Coady, M., de Jong, E. J., \& Harper, C. (2011). From preservice to practice: Mainstream teacher beliefs of preparation and efficacy with English language learners in the state of Florida. Bilingual Research Journal, 34(2), 223-229. http://dx.doi.org/10.1080/15235882.2011.597823

Cochran-Smith, M., \& Zeichner, K.M. (2005). Studying teacher education: The report of the AERA panel on research and teacher education. Lawrence Erlbaum Associates, Inc. Mahwah, NJ.

Cochran-Smith, M. (2001). Constructing outcomes in teacher education: Policy, practice and pitfalls. Education Policy Analysis Archives, 9(11).

Cochran-Smith, M. (2003). The multiple meanings of multicultural teacher education: A conceptual framework. Teacher Education Quarterly, 30(2), 7-26. 


\section{Macrothink}

International Journal of Education ISSN 1948-5476 2013, Vol. 5, No. 4

Cochran-Smith, M. (2008). Toward a theory of teacher education for social justice. The International Handbook of Educational Change. http://dx.doi.org/10.1007/978-90-481-2660-6_27

Cochran-Smith, M., \& S. L. Lytle. (2009). Inquiry as stance: Practitioner research for the next generation. New York: Teachers College Press.

Crawford, A. (2005). Communicative Approaches to Second Language Acquisition. LBD Publishers. Los Angeles, CA. http://dx.doi.org/10.1598/0872074552.7

Cummins, J. (2005). Teaching the Language of Academic Success: A Framework for School-Based Language Policies. LBD Publishers. Los Angeles, CA.

Darling-Hammond, L (2005). Teaching as a profession: Lessons in teacher preparation and professional development. Phi Delta Kappan, 87(3), 237-240.

Darling-Hammond, L., \& McLaughlin, M.W. (2011) Policies that support professional development in an era of reform. Phi Delta Kappan, 92(6), 81-92.

Darling-Hammond, L. (2006). Constructing 21st-century teacher education. Journal of Teacher Education, 57(10), 1-15. http://dx.doi.org/10.1177/0022487105285962

Darling-Hammond, L. (2010). Restoring our schools. The Nation, 290(23), 14-20.

Darling-Hammond, L. (2011). Soaring systems. Education Review, 24(1), 24-33.

Darling-Hammond, L. (2012). Redlining our schools. The Nation, 294(5), 11-15.

Darling-Hammond, L., \& Baratz-Snowden, J. (2005). A good teacher in every classroom: Preparing the highly qualified teachers our children deserve. San Francisco: Jossey-Bass.

Durgunoglu, A., \& Hughes, T. (2010). How prepared are the U.S. preservice teachers to teach English Language Learners? International Journal of Teaching and Learning in Higher Education, 22(1), 32-41.

Fitts, S., \& Gross, L. (2012). Teacher candidates learning from English learners: Constructing concepts of language and culture in Tuesday's tutors after-school program. Teacher Education Quarterly, 39(4), 75-95.

Gay, G. (1993). Building cultural bridges: A bold proposal for teacher education. Education and Urban Society, 25(3), 285-289.

Irvine, J., \& Armento, B. (2001). Culturally responsive teaching: Lesson planning for elementary and middle schools. Boston: McGraw-Hill.

Jaquith, A., Mindich, D., Wei, R., \& Darling-Hammond, L. (2011). Teacher professional learning in the U.S.: Case studies of state policies and strategies. Education Digest, 77(2), 33-39. 
Krashen, S. (2005). Bilingual Education and Second Language Acquisition Theory. LBD Publishers. Los Angeles, CA.

Menken, K. Kleyn, T., \& Chae, N. (2009). Spotlight on long-term English language learners: Characteristics and prior schooling experiences of an invisible population. International Multilingual Research Journal, 6, 121-142. http://dx.doi.org/10.1080/19313152.2012.665822

Menken, K., \& Kleyn, T. (2009). The multiple meanings of multicultural teacher education: A conceptual framework. Educational Leadership, 66(7).

Morrell, J. (2010). Teacher preparation and diversity: When American preservice teachers aren't white and middle class. International Journal of Multicultural Education, 12(1), $1-17$.

National Commission on Teaching and America's Future. (1996). What matters most: Teaching for America's future. New York: Columbia University, Teachers College.

NCES. (2003). School and Staffing Survey, 1999-2000. Washington, DC: National Center for Education Statistics, U.S. Department of Education. http://www.nces.ed.gov/surveys/sass

Nieto, S. (1994). Lessons from students on creating a chance to dream. Harvard Education Review, 64(4), 392-426.

Nieto, S. (2000). Placing equity front and center: Some thoughts on transforming teacher education for a new century. Journal of Teacher Education, 51(3), 180-187. http://dx.doi.org/10.1177/0022487100051003004

Nieto, S. (2005). Why we teach. Teachers College Press. New York, NY.

Olsen, L. (2010.). Changing Course for Long-term English Learners. Leadership, 40(2), 30-33.

Pepper, S., Hartman, K., \& Blackwell, J. (2012). Creating an environment of education excellence: The University of Mississippi-PDS partnership-the evolution continues. School University Partnerships, 5(1), 74-88.

Scherer, M. (2012). The challenges of supporting new teachers: A conversation with Linda Darling-Hammond. Educational Leadership, 69(8), 18-23.

Valentine, S. (2006). Addressing diversity in teacher education programs. Education, 127(2), 196-202.

Villegas, A. M., \& Lucas, T. (2002). Educating culturally responsive teachers: A coherent approach. Albany, NY: SUNY Press.

Vogt, M. (2009). Teachers of English learners: Issues of preparation and professional development. College Reading Association Yearbook, 30, 23-36. 


\section{Macrothink}

International Journal of Education ISSN 1948-5476 2013, Vol. 5, No. 4

Webster, N., \& Valeo, A. (2011). Teacher preparedness for a changing demographic of language learners. TESL Canada journal, 28(2), 150-128.

\section{Copyright Disclaimer}

Copyright reserved by the author(s).

This article is an open-access article distributed under the terms and conditions of the Creative Commons Attribution license (http://creativecommons.org/licenses/by/3.0/). 